\title{
Predictability of the individual clinical outcome of extracorporeal shock wave therapy for cellulite
}

This article was published in the following Dove Press journal:

Clinical, Cosmetic and Investigational Dermatology

23 May 2014

Number of times this article has been viewed

Kai-Uwe Schlaudraff'

Maren C Kiessling ${ }^{2}$

Nikolaus BM Császár ${ }^{2}$

Christoph Schmitz ${ }^{2}$

'Concept Clinic, Geneva, Switzerland; ${ }^{2}$ Department of Anatomy II, LudwigMaximilians-University of Munich, Munich, Germany
Correspondence: Christoph Schmitz

Department of Anatomy II, Ludwig-Maximilians-University,

Pettenkoferstrasse, Munich,

80336 Germany

Tel +49892 I807 2620

Fax +49892 I807 2683

Email christoph_schmitz@med.unimuenchen.de
Background: Extracorporeal shock wave therapy has been successfully introduced for the treatment of cellulite in recent years. However, it is still unknown whether the individual clinical outcome of cellulite treatment with extracorporeal shock wave therapy can be predicted by the patient's individual cellulite grade at baseline, individual patient age, body mass index (BMI), weight, and/or height.

Methods: Fourteen Caucasian females with cellulite were enrolled in a prospective, singlecenter, randomized, open-label Phase II study. The mean ( \pm standard error of the mean) cellulite grade at baseline was $2.5 \pm 0.09$ and mean BMI was $22.8 \pm 1.17$. All patients were treated with radial extracorporeal shock waves using the Swiss DolorClast ${ }^{\circledR}$ device (Electro Medical Systems, S.A., Nyon, Switzerland). Patients were treated unilaterally with 2 weekly treatments for 4 weeks on a randomly selected side (left or right), totaling eight treatments on the selected side. Treatment was performed at 3.5-4.0 bar, with 15,000 impulses per session applied at $15 \mathrm{~Hz}$. Impulses were homogeneously distributed over the posterior thigh and buttock area (resulting in 7,500 impulses per area). Treatment success was evaluated after the last treatment and 4 weeks later by clinical examination, photographic documentation, contact thermography, and patient satisfaction questionnaires.

Results: The mean cellulite grade improved from $2.5 \pm 0.09$ at baseline to $1.57 \pm 0.18$ after the last treatment (ie, mean $\delta$ - 1 was 0.93 cellulite grades) and $1.68 \pm 0.16$ at follow-up (ie, mean $\delta$-2 was 0.82 cellulite grades). Compared with baseline, no patient's condition worsened, the treatment was well tolerated, and no unwanted side effects were observed. No statistically significant (ie, $P<0.05$ ) correlation was found between individual values for $\delta-1$ and $\delta-2$ and cellulite grade at baseline, BMI, weight, height, or age.

Conclusion: Radial shock wave therapy is a safe and effective treatment option for cellulite. The individual clinical outcome cannot be predicted by the patient's individual cellulite grade at baseline, BMI, weight, height, or age.

Keywords: acoustic wave therapy, AWT, extracorporeal pulse activation therapy, EPAT, radial shock wave therapy, RSWT

\section{Introduction}

Gynoid lipodystrophy, better known as cellulite, is the most common lipodystrophic disease and is found in $85 \%$ of post-adolescent women. ${ }^{1-4}$ Cellulite usually develops in particular anatomical areas, such as the thighs, buttocks, abdomen, and upper arms, and becomes visible through its classical "orange peel" appearance, characterized by an irregular, dimpled skin surface with thinning of the epidermis/dermis and the presence of nodular clusters of fat cells. ${ }^{1-4}$ It represents not only a cosmetic concern 
for women, but often becomes a major psychological problem, impairing sporting activities, choice of clothing, and social interaction.

The pathophysiology of cellulite is related to various predisposing factors, such as biotype, heredity, ethnic background, body weight, age, hormonal changes, smoking, and genetic predisposition. ${ }^{1,2,4-6}$ Four main hypotheses regarding the etiopathogenesis of cellulite have emerged over recent decades: a different anatomical conformation of the subcutaneous tissue in women compared with men; ${ }^{7,8}$ changes in the biomechanical properties of epidermal and dermal tissues ${ }^{8}$ excessive hydrophilia of the extracellular matrix increasing interstitial pressure and causing edema of the fatty tissue $;^{9}$ and alterations in both microvascular and lymphatic circulation resulting in the often painful protrusion of subcutaneous adipose tissue into the lower reticular dermis, causing distinctive mattress-like surface irregularities. ${ }^{10}$ However, these hypotheses are mutually conflicting and do not consider recent advances in our understanding of the complex physiopathology of the adipose organ. ${ }^{10}$ For instance, one cannot exclude that inflammation also contributes to the formation of cellulite. ${ }^{11,12}$

Nevertheless, various treatments for cellulite have been developed over recent decades, focusing on skin tightening with radiofrequency or lasers, improving blood and lymphatic circulation using both physical treatments and pharmacotherapy, and treating deeper deformities with surgical subcision, laser treatments, ultrasound devices, or liposuction (summarized in Table 1). However, there is no single treatment of cellulite that is completely effective. ${ }^{13,14}$

Extracorporeal shock wave therapy (ESWT) and radial shock wave therapy (RSWT) have been introduced as safe and effective treatment options for cellulite. ${ }^{15-23}$ A shock wave is an acoustic pressure wave that is produced in any elastic medium, such as air, water, or even a solid substance. ${ }^{24,25}$ Shock waves differ from sound waves in that the wave front, where compression takes place, is a region of sudden change in stress and density. ${ }^{24,25}$ Both focused shock waves (ESWT) and radial shock waves (RSWT) are characterized by a high positive peak pressure (in $\mathrm{mPa}$ ), a fast initial rise

Table I Various therapies for cellulite and their level of evidence based on published studies

\begin{tabular}{|c|c|c|c|c|c|}
\hline \multirow[t]{2}{*}{ Treatment } & \multicolumn{5}{|c|}{ Related studies and their level of evidence* } \\
\hline & IB & IIA & IIB & III & IV \\
\hline \multirow[t]{5}{*}{ ESWT/RSWT } & Sattler et al $\left.\right|^{15}$ & Braun et $\mathrm{al}^{18}$ & & & Kuhn et $\mathrm{a}^{23}$ \\
\hline & Knobloch et al ${ }^{16}$ & Angehrn et al ${ }^{19}$ & & & \\
\hline & Russe-Wilflingseder et a ${ }^{17}$ & Christ et $\mathrm{al}^{20}$ & & & \\
\hline & & Christ et $\mathrm{al}^{21}$ & & & \\
\hline & & Adatto et $\mathrm{al}^{22}$ & & & \\
\hline \multirow[t]{2}{*}{ Radiofrequency } & Mlosek et al ${ }^{50}$ & Nootheti et $\mathrm{al}^{51}$ & Sadick and Mulholland ${ }^{53}$ & & \\
\hline & & Goldberg et a $\left.\right|^{52}$ & Sadick and Magro ${ }^{54}$ & & \\
\hline \multirow[t]{2}{*}{ Laser-assisted lipolysis } & Prado et a ${ }^{55}$ & & & & Katz et $\mathrm{al}^{57}$ \\
\hline & Nagy and Vanek ${ }^{56}$ & & & & Kim and Geronemus ${ }^{58}$ \\
\hline Topical herbs and retinol & Lis-Balchin ${ }^{59}$ & Kligman et $\mathrm{al}^{60}$ & & & \\
\hline $\begin{array}{l}\text { Topical phosphatidylcholine } \\
\text { and LED }\end{array}$ & Saski et $a^{\mid 61}$ & & & & \\
\hline ESWT + cryolipolysis & & Ferraro et al ${ }^{44}$ & & & \\
\hline Focused ultrasound & & Moreno-Moraga et $\mathrm{a}^{62}$ & & & \\
\hline Endermology & & Collis et $\mathrm{al}^{63}$ & Chang et $\mathrm{a}^{64}$ & & \\
\hline \multirow[t]{2}{*}{ Weight loss } & & & Smalls et $a^{65}$ & & \\
\hline & & & Mauriège et $\mathrm{a}^{66}$ & & \\
\hline \multirow[t]{2}{*}{ Mesotherapy } & & & Hexsel et al ${ }^{67}$ & & \\
\hline & & & Rotunda et $\mathrm{al}^{68}$ & & \\
\hline \multirow[t]{2}{*}{ Carboxy therapy } & & & Brandi et al ${ }^{69}$ & & \\
\hline & & & Brandi et $\mathrm{al}^{70}$ & & \\
\hline Liposuction & & & & Coleman $^{71}$ & \\
\hline Lipolysis with topical & & & & & Môle $^{72}$ \\
\hline \multicolumn{6}{|l|}{ phosphatidylcholine injections } \\
\hline Cryolipolysis & & & & & Manstein et $\mathrm{a}^{73}$ \\
\hline Subcision & & & & & Hexsel and Mazzuco ${ }^{74}$ \\
\hline
\end{tabular}

Notes: *Level IB: evidence from at least one randomized controlled trial. Level IIA: evidence from at least one controlled study without randomization. Level IIB: evidence from at least one other type of experimental study. Level III: evidence from nonexperimental descriptive studies, such as comparative studies, correlation studies, and case control studies. Level IV: evidence from expert committee reports or opinions or clinical experience of respected authorities, or both. ${ }^{75}$

Abbreviations: ESWT, extracorporeal shock wave therapy; RSWT, radial shock wave therapy; LED, light-emitting diode. 
in pressure (approximately a few microseconds or less), a diffraction-induced tensile wave following the positive pressure amplitude that can generate cavitation, and a short life cycle of approximately 10-20 $\mu$ seconds (Figure 1). ${ }^{24-29}$ Extracorporeal shock wave lithotripsy is widely used for stone management in urology. ${ }^{30}$ ESWT and RSWT are byproducts of lithotripter technology. Since the late 1980s, they have been introduced into treatment for various diseases of the musculoskeletal system, such as plantar fasciopathy, Achilles tendinopathy, medial tibial stress syndrome, greater trochanteric pain syndrome, lateral and medial epicondylitis, and calcifying tendonitis of the shoulder. ${ }^{27-29,31,32}$ Shock waves have both a direct and indirect effect on treated tissues. The direct effect is the result of the energy of the shock wave being transferred to the targeted tissues. The indirect effect is the result of the creation of cavitation bubbles in the treated tissue. ${ }^{24,25,29}$ It has been hypothesized that both the direct and indirect effects produce a biological response in the treated tissues. $^{24,25,29}$

ESWT devices share two technical key characteristics of extracorporeal shock wave lithotripsy devices used for stone management, namely the electrohydraulic, electromagnetic, or piezoelectric generation of pressure waves and the generation of focused or so-called defocused pressure waves. ${ }^{29,33}$ Radial shock waves are generated ballistically, ie, by accelerating a bullet that strikes an applicator, transforming the kinetic energy of the bullet into a radially expanding pressure wave (Figure 1). ${ }^{29,32,33}$ In this regard, it is of note that, in several studies on ESWT/RSWT for cellulite, the therapy was termed acoustic wave therapy (AWT) $)^{15,17,20,22}$ or extracorporeal pulse activation therapy (EPAT). ${ }^{21,22}$ The terms AWT and EPAT are proprietary names of the manufacturer of the corresponding devices (Storz Medical, Tägerwillen, Switzerland; see also Russe-Wilfingseder et $\mathrm{al}^{17}$ ). AWT is registered as “... non-medical electric and electronic apparatus and instruments for the generation and application of shock waves or pressure waves in the fields of cosmetics and beauty care", ${ }^{34}$ and EPAT as "... electronic apparatus and parts of the apparatus for generating and applying pressure or shock waves for use in the fields of cosmetics and beauty care". 35 The similarity between AWT, EPAT, and RSWT has been addressed in several papers in the literature. . $1,36,37^{2}$

Unaddressed in the studies on ESWT/RSWT for cellulite carried out to date ${ }^{15-23}$ is whether the individual clinical outcome of the therapy can be predicted by the patient's cellulite grade at baseline, age, body mass index (BMI), weight, height, and/or age. This was addressed in the present study using RSWT. We hypothesized that the individual clinical outcome of RSWT for cellulite can be predicted by the patient's cellulite grade at baseline and the patient's BMI.

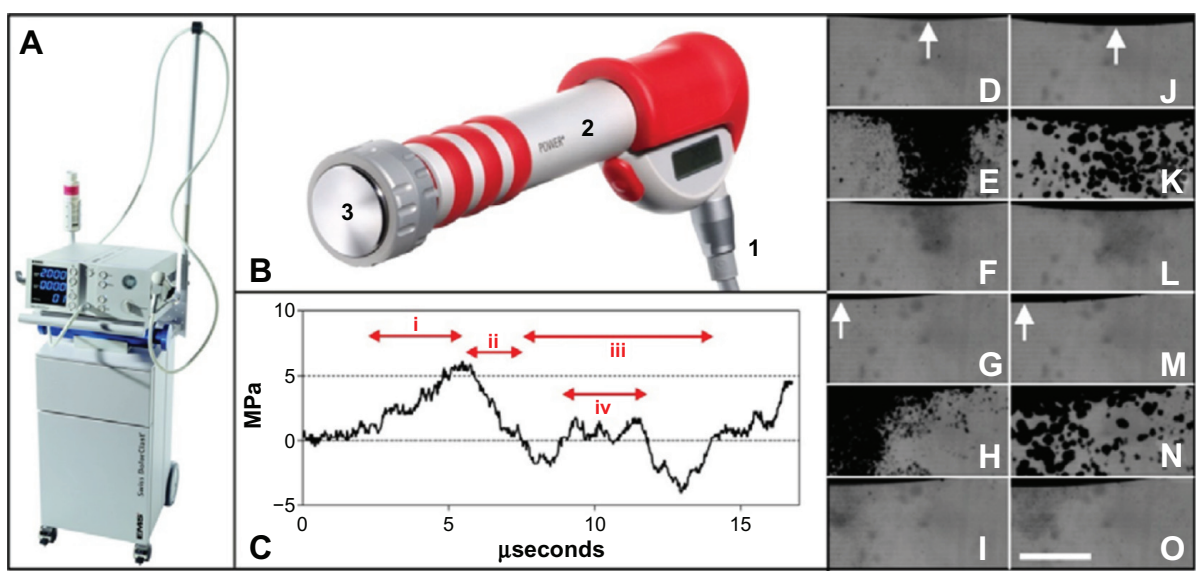

Figure I Principles of radial shock wave technology.

Notes: (A) DolorClast ${ }^{\circledR}$ device (Electro Medical Systems SA, Nyon, Switzerland) used in the present study. (B) Power+ hand piece of the Swiss DolorClast device with the $36 \mathrm{~mm}$ applicator used in the present study. Compressed air (I) is used to fire a projectile within a guiding tube (2) that strikes a 36 mm diameter metal applicator (3) placed on the skin. The projectile generates stress waves in the applicator that transmit pressure waves noninvasively into tissue. (C) Pressure wave generated with the Swiss DolorClast device, measured at a distance of I mm from the applicator (Power+ hand piece, $36 \mathrm{~mm}$ applicator, device operated at 4 bar air pressure and I5 $\mathrm{Hz}$ impulse frequency as used in the present study). After a delay of approximately $2 \mu$ seconds, the pressure wave shows an increase in (positive) pressure (i), followed by a decrease in pressure (ii) with reaching zero at approximately $8 \mu$ seconds, a subsequent period of negative pressure (iii) interrupted by a period of positive pressure (iv). (D-O) Cavitation bubbles (black dots) in degassed water generated during the phase of negative pressure of radial shock waves generated with the Power+ hand piece and the $36 \mathrm{~mm}$ applicator of the Swiss DolorClast device operated at 4 bar air pressure at $15 \mathrm{~Hz}(\mathbf{D}-\mathbf{I})$ as used in the present study or at I Hz (J-O) either at the center of the applicator ( $\mathbf{D}, \mathbf{E}, \mathbf{F}, \mathbf{J}, \mathbf{K}$ and $\mathbf{L})$ or the edge of the applicator $(\mathbf{G}, \mathbf{H}, \mathbf{I}, \mathbf{M}, \mathbf{N}$ and $\mathbf{O})$. Note that the arrows point to the center of the applicator. Maximum cavitation is shown in $(\mathbf{E}, \mathbf{H}, \mathbf{K}$ and $\mathbf{N})$. The images shown in $(\mathbf{D}, \mathbf{G}, \mathbf{J}$ and $\mathbf{M})$ were taken approximately $\mathbf{I} .5$ mseconds before the cavitation maximum, and images shown in $(\mathbf{F}, \mathbf{I}, \mathbf{L}$ and O) were taken approximately 1.5 mseconds after the cavitation maximum. Cavitation lasted for approximately one mseconds. The pictures were taken with a high-speed CCD camera (Photron Ultima APX; Photron, Tokyo, Japan) with a framing rate of 300,000 frames per second and an exposure time of I/2,700,000 seconds. The scale bar in (O) represents $10 \mathrm{~mm}$. Note that the cavitation field (and thus the pressure field below the applicator) is broader when generating radial shock waves at I5 Hz (D-I) than at $\mathrm{I} \mathrm{Hz}(\mathrm{J}-\mathbf{O})$. This phenomenon is observed for many radial shock wave devices (Császár et al, submitted for publication). 


\section{Materials and methods}

\section{Study design}

Fourteen Caucasian females with cellulite were enrolled in a prospective, single-center, randomized, open-label Phase II study. The mean ( \pm standard error of the mean) patient age was $42.4 \pm 2.81(23-57)$ years. Mean BMI was $22.8 \pm 1.17$ (18.7-32.9). The inclusion and exclusion criteria are summarized in Table 2. Informed consent was obtained from each patient before treatment. The study was approved by the ethics committee of Canton Geneva (Geneva, Switzerland) under registration number GE 08-40 and by the Swiss Agency for Therapeutic Products (Swissmedic, Bern, Switzerland) under registration number 2009-MD-0005. The study is registered with ClinicalTrials.gov (NCT01974115). ${ }^{38}$

\section{Determination of cellulite grade}

The mean cellulite grade of the patients at baseline was $2.5 \pm 0.09$ (range 2-3). Cellulite grades were determined by clinical inspection of the patients' skin (documented by digital photography) and by contact thermography.

Photographs of the patients were taken before the treatment cycle and at each follow-up using a D80 digital camera system (Nikon, Tokyo, Japan), PocketWizard transceivers (LPA Design, Burlington, VT, USA), and StudioMax III lighting equipment (Photogenic Professional Lighting, Bartlett, IL, USA), with standardized lighting settings and distance to the patient at each photographic session. Patients were asked to fully contract the buttock muscles each time

Table 2 Inclusion and exclusion criteria applied in the present study

Inclusion criteria
Healthy women $<60$ years of age, with cellulite grade $2-3$
Unchanged hormonal treatment for $<6$ months
Commitment to the study and ability to follow the medical directions
during the study
Signed informed consent form
Exclusion criteria
Previous surgery in the treated area (especially liposuction)
Medical and/or cosmetic treatment of cellulite ongoing or within the last
3 months
Infection and/or tumor disease within the treatment area
Anticoagulation therapy and/or hemorrhagic disorders
Pregnancy
Significant weight fluctuations (caused by disease or diet)
Modified hormonal treatment
Drugs (eg, corticosteroids, nonsteroidal anti-inflammatories)
Vascular abnormalities
Previous treatment with ESWT/RSWT

Abbreviations: ESWT, extracorporeal shock wave therapy; RSWT, radial shock wave therapy. a photograph was taken. This aimed to fully show and standardize the appearance of the cellulite and thus to avoid any "softening effects" due to varying muscle tone that might change the visibility of the cellulite.

Contact thermography was performed using the Cell-Meter ${ }^{\circledR}$ System Professional Cellulite Thermodetector (IPS Srl, Milan, Italy) that was applied directly on the skin of the treated areas. The temperature is displayed in a color code, with brown-orange-yellow indicating cold areas $\left(29.5^{\circ} \mathrm{C}-30.5^{\circ} \mathrm{C}\right)$ and bluish shades indicating warm areas $\left(32^{\circ} \mathrm{C}-33.5^{\circ} \mathrm{C}\right)$. Cellulite grades, determined by clinical inspection of the skin, correlated well with the contact thermography data.

\section{Treatment}

All patients were treated with radial extracorporeal shock waves using the Swiss DolorClast device (Electro Medical Systems, SA, Nyon, Switzerland) and the Swiss DolorClast Power+ hand piece with the $36 \mathrm{~mm}$ applicator (Figure 1). Patients were positioned on a treatment table as indicated in Figure 2 and the areas of the posterior thigh and the anatomical buttock area were treated. The medial and lateral lines of the thigh served as borders of the treatment area which extended superiorly until the buttock crease and inferiorly $5 \mathrm{~cm}$ above the popliteal crease.

Patients were treated unilaterally with 2 weekly treatments for 4 weeks on a randomly selected side (left or right), totaling eight treatments on the selected side. After application of coupling gel, treatment was performed at 3.5-4.0 bar, with 15,000 impulses per session, and applied at $15 \mathrm{~Hz}$. Impulses were applied homogeneously over the posterior thigh and buttock area.
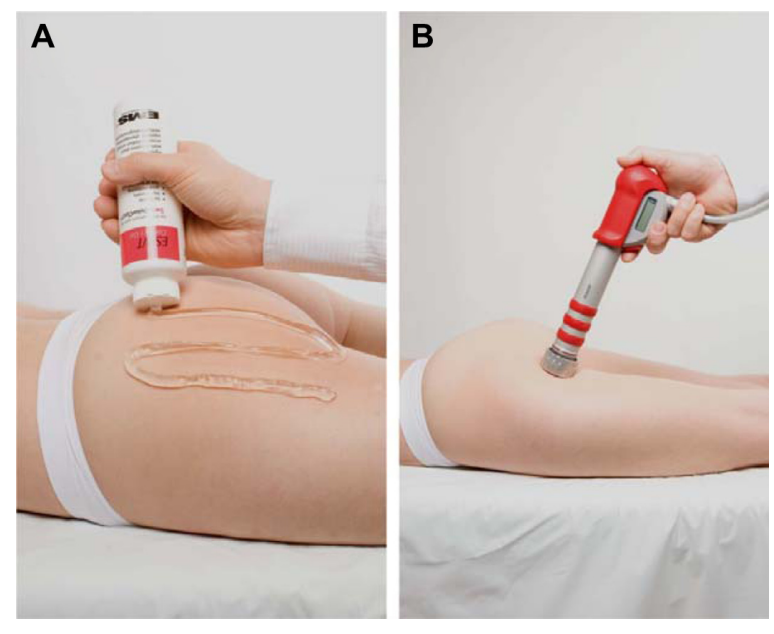

Figure 2 Radial shock wave therapy for cellulite.

Notes: (A) Application of coupling gel. (B) Treatment with the Power+ hand piece of the Swiss DolorClast ${ }^{\circledR}$ device (Electro Medical Systems, Nyon, Switzerland). 


\section{Evaluation of clinical outcome}

The condition of each patient's skin was evaluated before treatment, after the last treatment, and at a follow-up visit 4 weeks after the last treatment. At both the last treatment and at follow-up, patients completed a detailed questionnaire with scores for treatment comfort, pain intensity, and satisfaction, while also indicating undesired effects, such as bruising.

\section{Statistical analysis}

The mean and standard error of the mean were calculated for all investigated variables. Dependence of the clinical outcome of RSWT (calculated as the individual difference in cellulite grades either between baseline and after the last treatment $[\delta-1]$ or between baseline and follow-up [ $\delta-2]$ ) on the patients' initial cellulite grade at baseline, BMI, weight, height, age, pain during the treatment, feeling of comfort during treatment, and satisfaction at the end of treatment (or at the end of the follow-up period) was tested using Spearman's nonparametric rank correlation. Because $\delta$ - 1 and $\delta$ - 2 were each tested against eight variables, an effect was considered statistically significant if its associated $P$-value was smaller than $0.05 / 8=0.00625$ considering the Bonferroni correction for multiple hypothesis testing. ${ }^{39}$ Spearman's nonparametric rank correlation was also used for testing the relationship between $\delta-1$ and $\delta-2$. In this case, the effect was considered to be statistically significant if the associated $P$-value was smaller than 0.05 . Calculations were performed using
GraphPad Prism version 5.0 for Windows (GraphPad software, San Diego, CA, USA).

\section{Results}

The mean cellulite grade improved from $2.5 \pm 0.09$ (range 2-3) at baseline to $1.57 \pm 0.18$ (range $0.25-2.75$ ) at the end of the treatment (ie, the mean $\delta$-1 was 0.93 cellulite grades). At the end of the follow-up period, the mean cellulite grade was $1.68 \pm 0.16$, ranging between 0.5 and 2.75 (ie, the mean $\delta-2$ was 0.82 cellulite grades). The individual $\delta$ - 1 varied between 0 grades (ie, no improvement) and 1.75 grades, and the individual $\delta$-2 between 0 grades and 1.5 grades (Figure 3 ). Accordingly, compared with baseline, no patient's skin condition worsened during treatment and follow-up. The treatment was well tolerated and no unwanted side effects were observed (note that discomfort during treatment and reddening of the skin up to 24 hours after each treatment session are usual side effects of RSWT and were therefore not considered unwanted side effects).

No statistically significant (ie, $P<0.05 / 8$ ) correlation was found between $\delta-1$ or $\delta-2$ and cellulite grade at baseline, BMI, weight, height, age, pain during treatment, feeling of comfort during treatment, or satisfaction at the end of treatment (or at the end of the follow-up period, Figures 4 and 5).

For eleven of the 14 patients, the condition of the skin further improved or remained constant during the interval between the last treatment and follow-up (Figure 6).
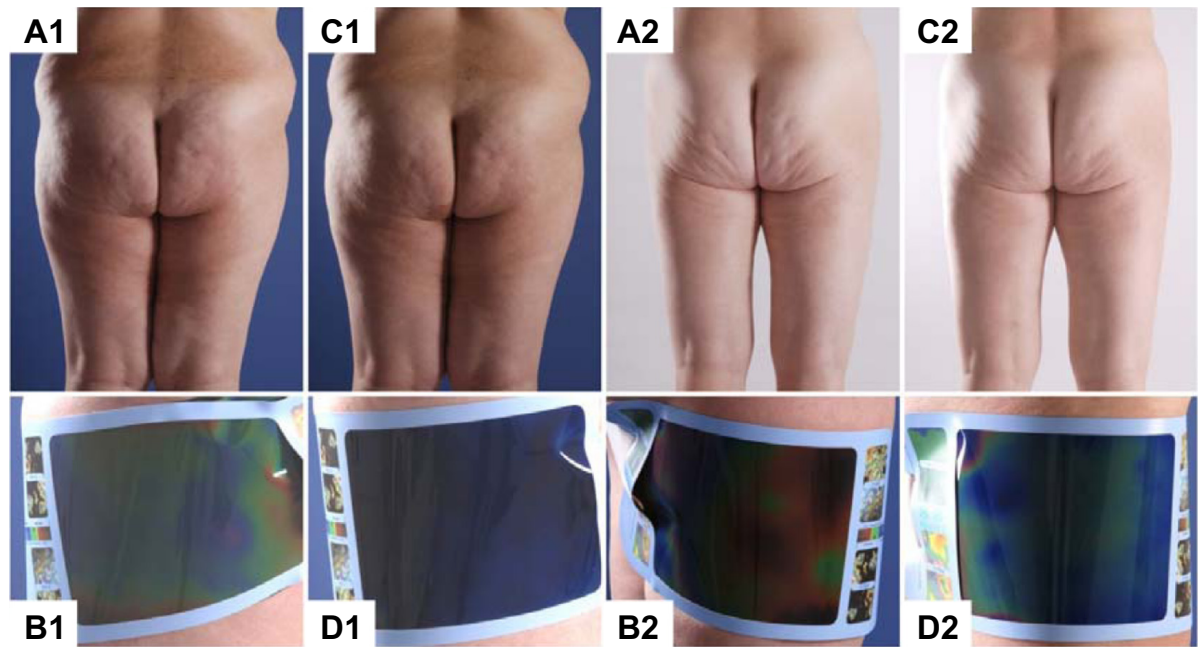

Figure 3 Treatment of two patients (I, 2) with cellulite using radial extracorporeal shock wave therapy.

Notes: (AI and A2) Clinical picture at baseline. (BI and B2) Contact thermography at baseline. (CI and C2) Clinical picture 4 weeks after the last treatment (follow-up). (DI and D2) Contact thermography at follow-up. (AI-DI) A 29-year-old female (body mass index 32.9 , weight $84.3 \mathrm{~kg}$, height I60 cm). Radial extracorporeal shock wave therapy performed on the left side improved the cellulite from grade 3 at baseline to grade $1-2$ at follow-up (ie, $\delta$ - 2 was I.5). Despite this objectively substantial treatment success, the patient's satisfaction was only 5 on a scale ranging from 0 (maximum dissatisfaction) to 10 (maximum satisfaction). (A2-D2) A 51 -year-old female (body mass index 20.8; weight $53.3 \mathrm{~kg}$; height $160 \mathrm{~cm}$ ). Radial extracorporeal shock wave therapy performed on the right side improved the cellulite from grade 2-3 at baseline to grade I-I.5 at follow-up (ie, $\delta$ - 2 was I.25). This patient was very satisfied with the treatment ( 9 on a scale ranging from 0 to I0). Patient consent was obtained to publish the above images. 

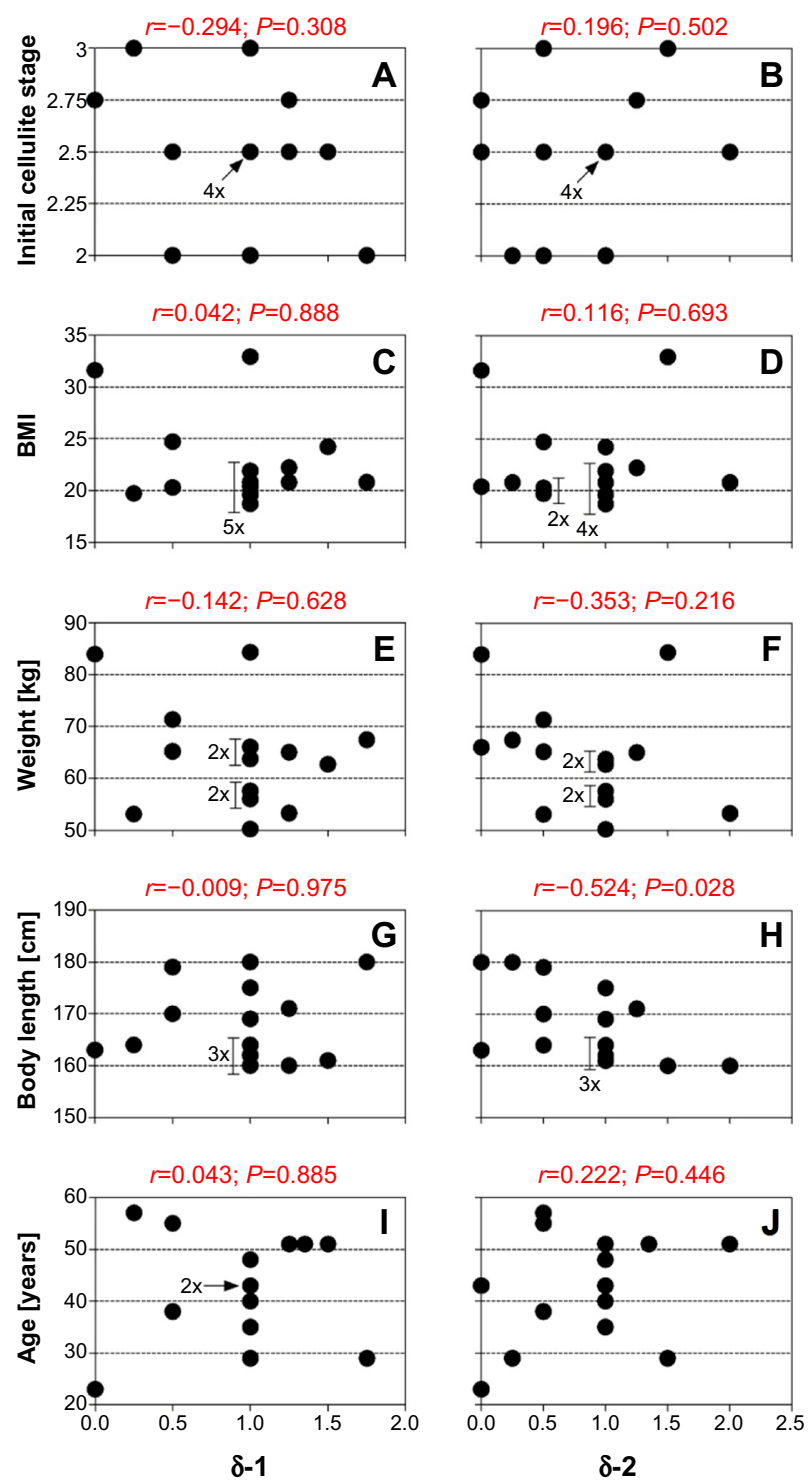

Figure 4 Clinical outcome of radial extracorporeal shock wave therapy for cellulite as a function of the patients' initial cellulite grade at baseline ( $\mathbf{A}$ and $\mathbf{B})$, BMI ( $\mathbf{C}$ and $\mathbf{D}$ ), weight (E and $\mathbf{F}$ ), height ( $\mathbf{G}$ and $\mathbf{H}$ ) and age ( $\mathbf{I}$ and $\mathbf{J}$ ) (calculated as individual difference in cellulite grades either between baseline and after the last treatment $[\delta-I]$ or between baseline and at follow-up [ $\delta-2]$, respectively; the higher $\delta-I$ and $\delta-2$, the better the treatment success).

Notes: Each dot represents an individual patient; overlapping data are indicated. The Spearman's nonparametric rank correlation coefficients $(r)$ and the corresponding $P$-values are provided in red on top of each panel.

Abbreviation: BMI, body mass index.

However, there was no statistically significant correlation between $\delta$-1 and $\delta$-2 $(P=0.105)$.

\section{Discussion}

The results of the present study are generally in line with earlier reports of successful treatment of cellulite with RSWT in the literature. ${ }^{15,17,20-22}$ RSWT can improve the clinical picture by one cellulite grade on average. However, to the authors' knowledge, the present study is the first to demonstrate that the individual clinical outcome of RSWT for cellulite cannot be predicted by the patient's individual cellulite grade at baseline, BMI, weight, height, or age. We hypothesize that the same applies to ESWT for cellulite.

In our clinical experience, the patient's perception of their individual cellulite grade and consequently their satisfaction with the result of treatment for cellulite varies widely from one patient to another and is truly subjective. Normally, patients with low cellulite grades are more demanding and therefore more difficult to manage in their expectations, even if there is an objectively confirmed clinical improvement. This was confirmed in our analysis because patient satisfaction, the most important end point of any treatment for cellulite, did not correlate with $\delta-1$ or $\delta-2$. There were patients with $\delta-1=1$ (ie, improvement by one cellulite grade) who were very satisfied, whereas other patients with $\delta-1=1$ were not satisfied at all (Figure 5E). For the clinical setting, this observation underlines the role of the therapist, who must correctly evaluate the suitability of the candidate for a cellulite treatment and must manage the patient's expectations accordingly. For studies evaluating existing or new cellulite treatments, this observation underscores the crucial importance of applying objective analytical methods, such as contact thermography and standardized photographic documentation (in full muscular contraction), because satisfaction scores may suffer from variations in their consistency. Note that individual patient satisfaction scores were either not reported or not correlated with individual objective outcome measures in the studies of ESWT/RSWT for cellulite published to date. ${ }^{15-23}$ Standardized yet easy clinical analysis of the severity of cellulite should include easy, effective, and reproducible measurement tools. In our opinion, clinical evaluation serves for classification of the cellulite grade, double contrast photography as applied in the present study provides a visual contour analysis, and contact thermography measures the superficial blood perfusion of the skin. Recoil and elasticity measurements, as applied in some studies of ESWT/RSWT for cellulite, ${ }^{15,20,21}$ are helpful in small treatment areas but may considerably vary over the length of a thigh depending on changing quality and thickness of the skin in the respective parts.

In recent years, ESWT/RSWT has become the best studied therapy option for cellulite (Table 1). This is most likely due to the fact that ESWT/RSWT is noninvasive, does not require administration of drugs, and can be easily accomplished within a few minutes per treatment session. It is justified to consider ESWT (ie, focused shock waves) and RSWT (ie, radial shock waves) as very similar therapeutic options for cellulite. This is due to the fact that the energy signatures of ESWT and RSWT share fundamental physical characteristics, such as high peak pressure, a fast initial rise in pressure, a low tensile amplitude 

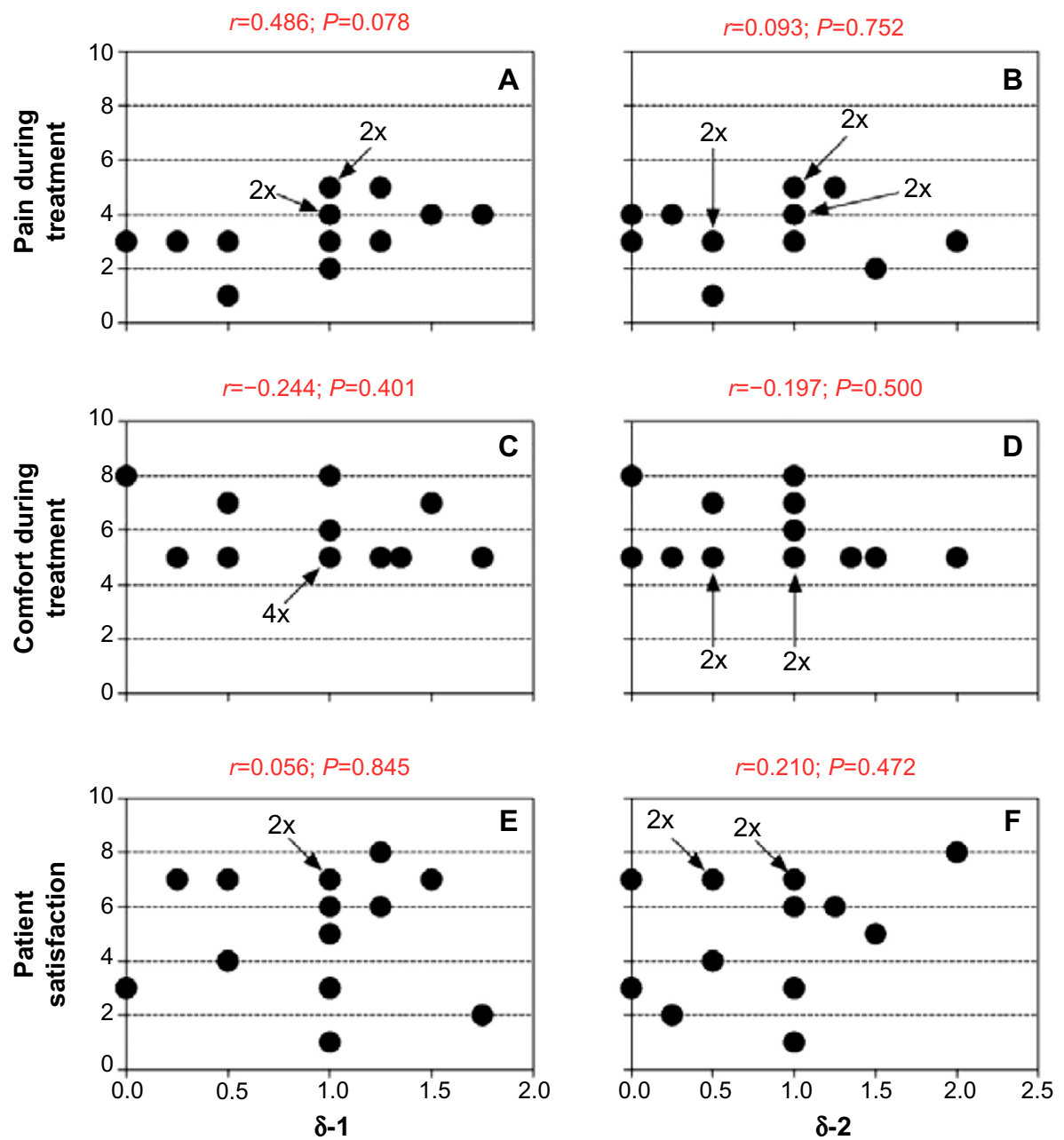

Figure $\mathbf{5}$ Clinical outcome of radial extracorporeal shock wave therapy for cellulite as a function of the patients' pain during the treatment (A and $\mathbf{B})$, the patients' feeling of comfort during treatment ( $\mathbf{C}$ and $\mathbf{D}$ ), and the patients' satisfaction with treatment ( $\mathbf{E}$ and $\mathbf{F})$ (calculated as individual difference in cellulite grades either between baseline and after the last treatment [ $\delta-I]$ or between baseline and at follow-up [ $\delta-2]$, respectively; the higher $\delta$-I and $\delta$-2, the better the treatment success).

Notes: Each dot represents an individual patient; overlapping data are indicated. Pain was assessed using a visual analog scale ranging from 0 (no pain) to 10 (maximum pain). The feeling of comfort was assessed using a scale ranging from 0 (maximum discomfort) to 10 (maximum comfort), and patients' satisfaction using a scale ranging from 0 (maximum dissatisfaction) to 10 (maximum satisfaction). The Spearman's nonparametric rank correlation coefficients $(r)$ and the corresponding $P$-values are provided in red on top of each panel.

that can generate cavitation, and a short life cycle. Some authors have offered the following physical definition of "real" shock waves: ${ }^{26,27}$ a high positive peak pressure, sometimes more than $100 \mathrm{mPa}$, but more often approximately 50-80 $\mathrm{mPa}$; a fast initial rise in pressure during a period of less than 10 nanoseconds; a low tensile amplitude (up to $10 \mathrm{mPa}$ ); a short life cycle of approximately $10 \mu$ seconds; and a broad frequency spectrum, typically in the range of $16-20 \mathrm{mHz}$. It is well known that radial shock waves do not fulfill the characteristics set out by this physical definition of real shock waves (see also Figure 1). ${ }^{29,40}$ Some ESWT devices generate pressure waves that fulfill the characteristics set out by this physical definition of real shock waves, whereas others do not. ${ }^{29,40,41}$ Among those ESWT devices that do not produce real shock waves is the electromagnetic Duolith ${ }^{\circledR}$ device (Storz Medical) ${ }^{41}$ that has recently been introduced into ESWT for cellulite. ${ }^{16}$ Another device that was used in several studies for treating cellulite is the D-Actor ${ }^{\circledR} 200$ (Storz Medical). ${ }^{15,17,22}$ The pressure waves generated by this device are termed "low-energy radial shockwaves" in the literature. ${ }^{42}$ In contrast, Russe-Wilflingseder et $\mathrm{al}^{17}$ described the D-Actor 200 device as a "vibrating massage system". Regardless of these different descriptions in the literature, the D-Actor 200 device is making use of the same construction principle as the Swiss DolorClast and accelerates a projectile by means of compressed air. For this reason, the D-Actor 200 device generates pressure waves that are very similar to the pressure waves generated by the Swiss DolorClast device, including the possibility of generating cavitation (Császár et al, submitted for publication).

Because the studies on ESWT/RSWT for cellulite considerably vary with respect to the level of evidence, shock 


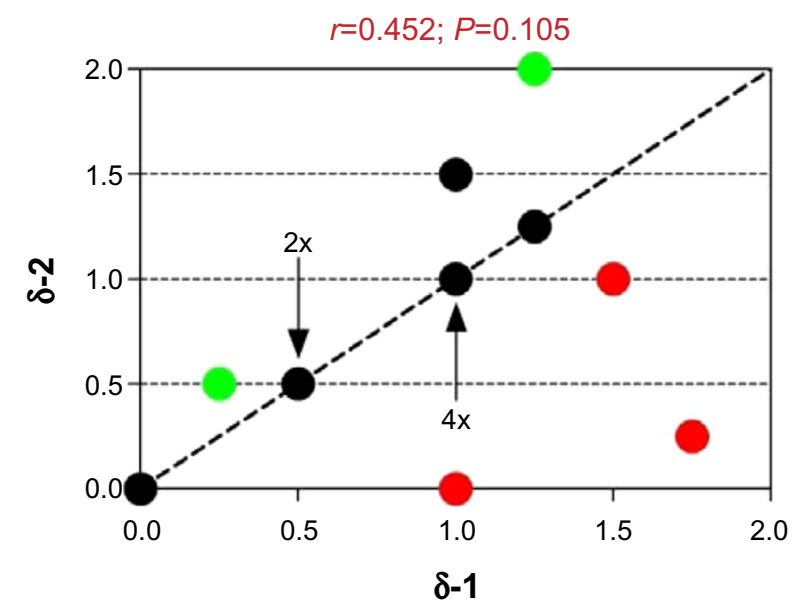

Figure 6 Relationship between the individual difference in cellulite grades between baseline and after the last treatment $(\delta-I)$ and between baseline and at follow-up $(\delta-2)$ after radial extracorporeal shock wave therapy for cellulite (the higher $\delta$-I and $\delta-2$, the better the treatment success).

Notes: Each dot represents an individual patient; overlapping data are indicated. Red, black, and green dots/asterisks indicate patients whose cellulite grade worsened, remained unchanged, or improved, respectively, during the followup period compared with the situation after the last treatment. The Spearman's nonparametric rank correlation coefficient $(r)$ and the corresponding $P$-value are provided in red on top of the panel.

wave device used, and treatment protocol, they are discussed separately, as follows.

In an early pilot study, Braun et a ${ }^{18}$ treated 20 patients with "severe cellulite measured with a pinch test" 18 using the electromagnetic DermaSelect ${ }^{\circledR}$ shock wave device (Storz Medical). The average age of the patients was 37.25 (range 19-56) years and their mean BMI was 29.18 (range 20-41.6). Each patient received six treatment sessions with 2,400 impulses per session on the left leg (the time interval between treatments, size of the treatment area, and energy flux density of the shock waves were not provided). According to the authors' subjective impressions of the treated leg and photographic analyses, a significant improvement in skin surface was shown for more than 70 percent of the patients. However, treatment success was not expressed according to changes in cellulite grades.

Angehrn et $\mathrm{a}^{19}$ treated 21 female patients with cellulite (grade 1, $\mathrm{n}=5$; grade 2, $\mathrm{n}=6$; grade $3, \mathrm{n}=10$ ) using defocused shock waves generated with the electrohydraulic ActiVitor-Derma $^{\circledR}$ device (SwiTech Medical, Kreuzlingen, Germany). Treatment consisted of 12 sessions at intervals of 3-4 days, treatment of the skin of the lateral left and right thigh with 4,000 impulses per thigh per treatment session, homogeneously distributed over an area of $160 \mathrm{~cm}^{2}$ per side with an energy flux density of $0.018 \mathrm{~mJ} / \mathrm{mm}^{2}$. BMI was 20-24 in ten patients, 25-29 in nine patients, 30-34 in one patient, and 35-40 in one patient. End points were subjective opinion of improvement and collagenometry measurements performed with the high-resolution ultrasound system, Collagenoson $^{\circledR}$ (Minhorst, Meudt, Germany). At the end of the treatment period, two patients showed clear worsening of collagenometry results compared with baseline, five patients showed some worsening, two patients showed no change, eight patients showed improvement, and four patients showed clear improvement compared with baseline. There was no correlation between the outcome of collagenometry and individual cellulite grade. Seventeen of the 21 patients (81\%) subjectively assessed their outcome as improved. Seven patients evaluated the treatment as not suitable (pain during treatment), six patients assessed it as suitable (no pain during treatment), and eight patients were indifferent. The authors concluded that their results provided evidence that low-energy defocused ESWT caused remodeling of the collagen within the dermis of the tested region.

Christ et al ${ }^{20,21}$ treated a total of 59 female patients with cellulite grade 2 or 3 with planar or radial shock waves generated with the electromagnetic Cellactor ${ }^{\circledR} \mathrm{SC} 1$ device (Storz Medical). Group 1 ( $\mathrm{n}=15$, mean age 44.6 years, mean BMI 24.4) was treated with planar shock waves generated with the C-Actor hand piece of the Cellactor SC1 device (six treatment sessions at intervals of 3-4 days, treatment of lateral and medial thigh areas as well as the buttocks, total of 3,200 impulses per treatment session with an energy flux density of $0.25 \mathrm{~mJ} / \mathrm{mm}^{2}$ homogeneously distributed over a total area of $20 \times 30 \mathrm{~cm})$. Group $2(\mathrm{n}=44$, mean age 45.5 years, mean BMI 25.3) was treated identically but with eight treatment sessions. End points were the elasticity of the skin measured with the DermaLab ${ }^{\circledR}$ device (Cortex Technology, Hadsund, Denmark) and the structure of the connective tissue in the dermis evaluated with the DermaScan ${ }^{\circledR}$ ultrasound device (Cortex Technology) before and after treatment. The mean skin elasticity in group 1 patients was improved by $46 \%$ after treatment and by $78 \%$ at 3-month follow-up compared with baseline. In group 2, the mean improvement in skin elasticity was $72 \%$ after treatment, $95 \%$ at 3-month follow-up, and $105 \%$ at 6 months after baseline. The structure of the connective tissue also improved between baseline and the 6-month follow-up. Statistical analysis was not performed to evaluate the impact of BMI on the results in this study.

Kuhn et a ${ }^{23}$ presented a case report concerning a 50-yearold woman with grade 3 cellulite on her left thigh treated with the ActiVitor-Derma device (four therapy sessions, 800 impulses per session, energy flux density $0.115 \mathrm{~mJ} / \mathrm{mm}^{2}$ ). Based on high frequency, high resolution ultrasound measurements, contact thermography, and histopathologic 
biopsies, the authors reported "some improvement in the epidermis and the extracellular matrix of the dermis". ${ }^{23}$

Sattler et $\mathrm{al}^{15}$ compared three treatments for cellulite. Group 1 (eleven patients, mean age 40 years, mean BMI 27) was treated with radial shock waves generated with the ballistic D-Actor 200 device (a mean of 6.2 treatment sessions, an average of 1,909 impulses per treatment session; device operated at 2.4-3.0 bar and a frequency of $15 \mathrm{~Hz}$ ). Group 2 (eleven patients, of whom nine were included in the analysis, mean age 34 years, mean BMI 23) was treated with planar shock waves generated with the C-Actor hand piece of the electromagnetic Cellactor SC1 (a mean of 6.1 treatment sessions, 1,000 impulses per treatment session with an energy flux density of $0.35 \mathrm{~mJ} / \mathrm{mm}^{2}$ ). Group 3 (eight patients, of whom seven were included in the analysis, mean age 40 years, mean BMI 23) was treated with a combined radial and planar shock wave protocol (a mean of 6.4 treatment sessions; 2,350 radial pulses on average followed by an average of 1,925 planar impulses per treatment session; radial impulses generated by operating the control unit at 2.6-3.0 bar; planar impulses with an energy flux density of $0.35 \mathrm{~mJ} / \mathrm{mm}^{2}$ ). Treatment was focused either on the buttock and dorsal thigh area or on the ventral thigh area, depending on the individual clinical picture. End points were visual impression of the skin (analyzed on photographs), patient satisfaction, and skin elasticity (measured with the DermaLab device) 3 months after the last treatment session compared with baseline. Patients in group 1 had the best result. Analysis of the photographs showed an optimum treatment result for five $(46 \%)$ patients, a satisfactory treatment result for three $(27 \%)$ patients, and a not significant treatment result for three (27\%) patients (specific criteria for optimum, satisfactory, and not significant were not specified). For patients in groups 2 and 3, the corresponding data were: an optimum treatment result in $1 / 9(11 \%)$ and $2 / 7$ (29\%), respectively; a satisfactory result in 5/9 (56\%) and 4/7 (57\%), respectively; and a not significant result in 3/9 (33\%) and 1/7 (14\%), respectively. A statistical analysis was not performed. It is of note that the authors did not recognize any change in skin elasticity as a result of shock wave treatment (mean data for group 1, $11.6 \mathrm{mPa}$ at baseline, $10.0 \mathrm{mPa}$ after treatment, and $10.1 \mathrm{mPa}$ at 3-month follow-up; mean data for group 2, $12.1 \mathrm{mPa}$ at baseline, $10.8 \mathrm{mPa}$ after treatment, and $12.1 \mathrm{mPa}$ at 3-month follow-up; mean data for group $3,10.3 \mathrm{mPa}$ at baseline, 10.4 after treatment, and 10.9 at 3 -month follow-up). The authors discussed the limitations of their study, ${ }^{15}$ ie, small numbers of patients, and differences in mean age and mean BMI between the groups, but concluded that treatment for cellulite with radial shock waves might be the best choice (as also performed in the present study).

Adatto et $\mathrm{al}^{22}$ treated 25 women of mean age 42.6 (range 27-63) years with a mean BMI of 24 (range 17-31) on one leg each with the ballistic D-Actor 200 device (a mean of six treatment sessions within 4 weeks with an average of 3,000 impulses per treatment session; device operated at 2.6-3.6 bar and with a frequency of $15 \mathrm{~Hz}$ ). The authors compared, for each patient, the treated leg with the untreated leg 1 week and 12 weeks after the last treatment. The evaluation was performed with measurements of skin elasticity using the DermaLab device. Furthermore, three-dimensional images of the skin structure were recorded using the DermaTOP ${ }^{\circledR}$ system (Eotech, Paris, France). Adatto et $\mathrm{al}^{22}$ found that skin elasticity, roughness elevation, and skin depression improved in a statistically significant manner on the treated legs compared with the untreated legs. They concluded that the D-Actor 200 device can be used effectively to treat cellulite without any side effects.

In a double-blind, randomized controlled trial, Knobloch et $\mathrm{al}^{16}$ randomly assigned 53 women to either focused shock waves using the electromagnetic Duolith device $(n=25$; mean age 41.4 years, mean BMI $24.2 \pm 3.2 \mathrm{~kg} / \mathrm{m}^{2}$; six sessions of ESWT every 1-2 weeks, with 2,000 impulses at $4 \mathrm{~Hz}$, and an energy flux density of $0.35 \mathrm{~mJ} / \mathrm{mm}^{2}$ ) or sham treatment ( $\mathrm{n}=28$; mean age 45.0 years, mean BMI $25.3 \pm 4.5 \mathrm{~kg} / \mathrm{m}^{2}$; six treatment sessions every 1-2 weeks, with 2,000 impulses and an energy flux density of $0.01 \mathrm{~mJ} / \mathrm{mm}^{2}$ ). In addition to ESWT or sham-ESWT, all patients underwent specific gluteal strength exercise training. Among other measurements, the primary end point was score on the photonumeric Cellulite Severity Scale (CSS) determined by two blinded, independent assessors. ESWT reduced the mean CSS from $10.9 \pm 3.8$ at baseline to $8.3 \pm 4.1$ at 12 weeks after the last treatment, whereas sham-ESWT did not (CSS at baseline

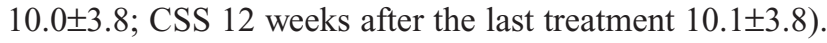
The difference between the two groups was statistically significant $(P=0.001)$. The authors concluded that the combination of ESWT and gluteal strength training was superior to gluteal strength training and sham-ESWT in moderate to severe cellulite in terms of CSS in a 3-month perspective. It remains unknown why females with documented cellulite grade 0 according to Nürnberger and Müller, ${ }^{7}$ ie, no cellulite, were eligible for and enrolled in this study. Furthermore, the authors described that they performed an intention-to-treat analysis because seven sham-treated women were lost to follow-up. However, they did not describe which of the various available methods for handling missing data in clinical trials they applied. ${ }^{43}$ 
Russe-Wilflingseder et $\mathrm{al}^{17}$ randomly assigned 16 women with cellulite (mean age $42.7 \pm 7.4$ years, mean BMI $22.5 \pm 1.85 \mathrm{~kg} / \mathrm{m}^{2}$ ) to either radial shock waves using the D-Actor 200 device ( $\mathrm{n}=11$; eight treatments once a week; 1,000 impulses at 2-3 bar air pressure applied using a DI15 deep impact transmitter (Storz Medical, Tägerwilen, Switzerland); 2,500 impulses at 3-5 bar applied by the D-Actor transmitter D20-S; frequency of shock waves not provided) or sham treatment ( $\mathrm{n}=5$; treatment protocol identical to the RSWT protocol but using a placebo hand piece that did not emit shock waves). Clinical outcome was assessed by a patient satisfaction questionnaire, weight control, measurements of thigh circumference, visual appearance of the skin in standardized photographs, and an analysis of images taken with a specially designed three-dimensional imaging system. Patients were investigated at baseline, before the last treatment, and at 1 and 3 months after the last treatment. By combining the results of four efficacy criteria at the two follow-up visits, the authors found a statistically significant improvement in the skin of women treated with radial shock waves but not for those treated with placebo. The authors concluded that radial shock wave treatment is safe and efficient for patients with cellulite. This is in line with the results of the present study.

Finally, a study by Ferraro et $\mathrm{al}^{44}$ warrants mention. The authors treated 37 women and 13 men with the Proshock Ice ${ }^{\circledR}$ device (Promoitalia, Milan, Italy) in five different areas: abdomen (five women, nine men), ankles (three women, one man), arms (five women, three men), buttocks (six women), and thighs (18 women). The authors described the Proshock Ice device as a combination of a controlled cooling system ("freezing probe") and a shock wave generator ("shock probe") with "pressure variable from 50 to $500 \mathrm{bar}$, and with impulses that have a duration of 8 mseconds" ${ }^{44}$ Unfortunately, it remains unclear what this actually means, given that radial shock wave devices are usually operated with an air pressure of $1-5 \mathrm{bar}$, have a maximum pressure of 100 bar $(10 \mathrm{mPa})$, and a duration of approximately 20 $\mu$ seconds. ${ }^{29,40}$ Ferraro et al ${ }^{44}$ applied tissue-specific (fat edematous cellulite, fibrous cellulite) treatments (freezing probe, shock probe) for 20-60 minutes every 15 days for 8 weeks (an average of 3.73 treatment sessions per patient). In addition to evaluations of each patient's individual subjective impression of the effect and objective clinical data such as skin-fold thickness and hepatic markers, the authors investigated skin biopsies of treated and untreated tissue to detect apoptosis, laminin, and collagen. The results showed statistically significant reductions in circumference of the treated body regions (abdomen, on average $6.86 \mathrm{~cm}$; ankles, on average $2.25 \mathrm{~cm}$; arms, on average
$2.75 \mathrm{~cm}$; buttocks, on average $5 \mathrm{~cm}$; thighs, on average $5.78 \mathrm{~cm}$ ) with no change in body weight. Microscopic investigation of the skin biopsies showed signs of dying fat cells (adipocytes) and an inflammatory process in the treated tissue. Ferraro et $\mathrm{a}^{44}$ discussed their method as a "noninvasive alternative to conventional liposuction for patients who require only small or moderate removal of adipose tissue and cellulite or who are not suitable candidates for surgical approaches to body contouring". 44

\section{Conclusion}

Several studies have demonstrated that cellulite can be treated effectively and safely with ESWT and RSWT. The main conclusion of the present study is that the individual clinical outcome of treatment with shock waves for cellulite cannot be predicted by the patient's cellulite grade at baseline, age, BMI, weight, or height.

Several questions regarding ESWT/RSWT for cellulite remain open and should be addressed in future studies. For instance, the striking difference between the results reported by Christ et $\mathrm{al}^{20,21}$ and those reported by Sattler et $\mathrm{al}^{15}$, regarding treatment-related changes in skin elasticity, require an independent reanalysis. The higher efficacy of RSWT relative to ESWT in treating cellulite ${ }^{15}$ should also be investigated. Presumably, the most important task will be to unravel the molecular and cellular mechanisms of shock waves in skin and fat tissue. In this regard, it is of note that several potential mechanisms have been proposed in the literature, comprising improved microcirculation, apoptosis of fat tissue, and improved lymph circulation (Table 3). Many of these mechanisms may be secondary to the activation of $\mathrm{C}$ nerve fibers in the skin by shock waves

Table 3 Various potential molecular and cellular mechanisms of action of shock waves on skin/fat tissue that have been proposed in the literature

\begin{tabular}{|c|c|}
\hline Proposed mechanisms & Reference \\
\hline Stimulation of blood and lymph circulation & Braun et al ${ }^{18}$ \\
\hline Increased membrane permeability & Braun et al ${ }^{18}$ \\
\hline Stimulation of the exchange of blood lipids & Braun et $\mathrm{al}^{18}$ \\
\hline Stimulation of metabolism & Angehrn et $\mathrm{al}^{19}$ \\
\hline Reduced oxidative stress & Christ et $\mathrm{a}^{21}$ \\
\hline Increased antioxidants (including ascorbic acid) & Siems et $\mathrm{a}^{76}$ \\
\hline $\begin{array}{l}\text { Induction of neocollagenogenesis and } \\
\text { neoelastinogenesis }\end{array}$ & Kuhn et $\mathrm{a}^{23}$ \\
\hline Increased angiogenesis & Ferraro et $\mathrm{al}^{44}$ \\
\hline $\begin{array}{l}\text { Expression of vascular endothelial growth factor, } \\
\text { endothelial nitric oxide synthase, and proliferating } \\
\text { cell nuclear antigen }\end{array}$ & Angehrn et al ${ }^{19}$ \\
\hline Apoptosis of fat cells triggered by inflammation & Ferraro et $\mathrm{al}^{44}$ \\
\hline $\begin{array}{l}\text { Activation of } C \text { nerve fibers in the skin and release } \\
\text { of substance } P\end{array}$ & Present study \\
\hline
\end{tabular}


and the release of substance $\mathrm{P}^{45,46}$ Substance $\mathrm{P}$ is one of the body's neurotransmitters for pain and heat, ${ }^{47}$ and is responsible for causing slight discomfort during and after shock wave treatment. ${ }^{29}$ Capsaicin is a neurotoxin that can deplete sensory nerves of their content of substance $\mathrm{P}^{48} \mathrm{~A}$ recent study showed an age-related decrease in thrombomodulin-positive cells and vascularity in the skin, and demonstrated that topic application of capsaicin to the skin may boost factor XIIIa-positive dendrocytes, thrombomodulin-positive cells, and the blood vessel network of the skin. ${ }^{49}$

\section{Acknowledgments}

The authors thank Nicholas Angstman for English language and grammatical technical support.

\section{Author contributions}

K-US, MCK, NBMC and CS provided substantial contributions to conception and design, acquisition of data, or analysis and interpretation of data; took part in either drafting the article or revising it critically for important intellectual content; gave final approval of the version to be published, and have agreed to be accountable for all aspects of the work in ensuring that questions related to the accuracy or integrity of any part of the work are appropriately investigated and resolved.

\section{Disclosure}

K-US has served as a paid consultant for and received benefits from Electro Medical Systems (Nyon, Switzerland), the manufacturer and distributor of the Swiss DolorClast radial shock wave device. MCK and NBMC report no conflicts of interest. CS serves as a paid consultant for and receives benefits from Electro Medical Systems.

\section{References}

1. Rossi AB, Vergnanini AL. Cellulite: a review. J Eur Acad Dermatol Venereol. 2000;14:251-262.

2. Avram MM. Cellulite: a review of its physiology and treatment. J Cosmet Laser Ther. 2004;6:181-185.

3. Khan MH, Victor F, Rao B, Sadick NS. Treatment of cellulite: Part I. Pathophysiology. J Am Acad Dermatol. 2010;62:361-370.

4. de la Casa Almeida M, Suarez Serrano C, Rebollo Roldán J, Jiménez Rejano JJ. Cellulite's aetiology: a review. J Eur Acad Dermatol Venereol. 2013;27:273-278.

5. Emanuele E, Bertona M, Geroldi D. A multilocus candidate approach identifies ACE and HIF1A as susceptibility genes for cellulite. $J$ Eur Acad Dermatol Venereol. 2010;24:930-935.

6. Stavroulaki A, Pramantiotis G. Cellulite, smoking and angiotensinconverting enzyme (ACE) gene insertion/deletion polymorphism. J Eur Acad Dermatol Venereol. 2011;25:1116-1117.

7. Nürnberger F, Müller G. So-called cellulite: an invented disease. J Dermatol Surg Oncol. 1978;4:221-229.

8. Rosenbaum M, Prieto V, Hellmer J, et al. An exploratory investigation of the morphology and biochemistry of cellulite. Plast Reconstr Surg. 1998;101:1934-1939.
9. Smalls LK, Lee CY, Whitestone J, Kitzmiller WJ, Wickett RR, Visscher MO. Quantitative model of cellulite: three-dimensional skin surface topography, biophysical characterization, and relationship to human perception. J Cosmet Sci. 2005;56:105-120.

10. Lotti T, Ghersetich I, Grappone C, Dini G. Proteoglycans in so-called cellulite. Int J Dermatol. 1990;29:272-274.

11. Terranova F, Berardesca E, Maibach H. Cellulite: nature and aetiopathogenesis. Int J Cosmet Sci. 2006;28:157-167.

12. Avram MM, Avram AS, James WD. Subcutaneous fat in normal and diseased states: 1. Introduction. J Am Acad Dermatol. 2005;53: 663-670.

13. Khan MH, Victor F, Rao B, Sadick NS. Treatment of cellulite: Part II Advances and controversies. J Am Acad Dermatol. 2010;62:373-384.

14. Rossi AM, Katz BE. A modern approach to the treatment of cellulite. Dermatol Clin. 2014;32:51-59.

15. Sattler G, Pohl U, Raegener K. [Pilot study acoustic wave therapy (AWT) for cellulite]. Aesthet Dermatol. 2008;2:17-25. German.

16. Knobloch K, Joest B, Krämer R, Vogt PM. Cellulite and focused extracorporeal shockwave therapy for non-invasive body contouring: a randomized trial. Dermatol Ther. 2013;3:143-155.

17. Russe-Wilflingseder K, Russe E, Vester JC, Haller G, Novak P, Krotz A. Placebo controlled, prospectively randomized, double-blinded study for the investigation of the effectiveness and safety of the acoustic wave therapy $\left(\mathrm{AWT}^{\mathbb{}}\right)$ for cellulite treatment. $J$ Cosmet Laser Ther. 2013; 15:155-162.

18. Braun MT, Daser A, Wroblewska KK. [Effects of shock wave therapy on pathological changes in subcutaneous adipose tissue. A pilot study]. Aesthet Dermatol. 2005;4:11-17. German.

19. Angehrn F, Kuhn C, Voss A. Can cellulite be treated with low-energy extracorporeal shock wave therapy? Clin Interv Aging. 2007;2: 623-630.

20. Christ C, Brenke R, Sattler G, Gabriel S, Siems W, Daser A. [Incerase of skin elasticity and revitalization of the dermis in cellulite and connective tissue weakness by extracorporeal acoustic wave therapy]. Aesthet Dermatol. 2008a;1:6-14. German.

21. Christ C, Brenke R, Sattler S, Siems W, Novak P, Daser A. Improvement in skin elasticity and dermal revitalization in the treatment of cellulite and connective tissue weakness by means of extracorporeal pulse activation therapy: EPAT. Aesthet Surg J. 2008;28:538-544.

22. Adatto M, Adatto-Neilson R, Servant JJ, Vester J, Novak P, Krotz A. Controlled, randomized study evaluating the effects of treating cellulite with AWT/EPAT. $J$ Cosmet Laser Ther. 2010;12:176-182.

23. Kuhn C, Angehrn F, Sonnabend O, Voss A. Impact of extracorporeal shock waves on the human skin with cellulite: a case study of an unique instance. Clin Interv Aging. 2008;3:201-210.

24. Ueberle F. Shock wave technology. In: Siebert W, Buch M, editors Extracorporeal Shock Waves in Orthopaedics. 1st ed. Berlin, Germany: Springer; 1998:59-87.

25. Ueberle F. Einsatz von Stoßwellen in der Medizin [Application of shock waves in medicine]. In: Kramme R, editor. Medizintechnik. 1st ed. Berlin, Germany: Springer; 2007:483-513. German.

26. Schleberger R, Delius M, Dahmen GP, et al. Orthopaedic extracorporeal shock wave therapy (ESWT). Method analysis and suggestion of a prospective study design - consensus report. In: Chaussy C, Eisenberger F, Jocham D, Wilbert D, editors. High Energy Shock Waves in Medicine. 1st ed. Stuttgart, Germany: Thieme; 1997.

27. Ogden JA, Tóth-Kischkat A, Schultheiss R. Principles of shock wave therapy. Clin Orthop Relat Res. 2001;387:8-17.

28. Rompe JD, Furia J, Weil L, Maffulli N. Shock wave therapy for chronic plantar fasciopathy. Br Med Bull. 2007;81-82:183-208.

29. Schmitz C, Császár NB, Rompe JD, Chaves H, Furia JP. Treatment of chronic plantar fasciopathy with extracorporeal shock waves (review). J Orthop Surg Res. 2013;8:31.

30. Rassweiler JJ, Knoll T, Köhrmann KU, et al. Shock wave technology and application: an update. Eur Urol. 2011;59:784-796.

31. Gerdesmeyer L, Weil LS. Extracorporeal Shock Wave Therapy. Technologies Basics Clinical Results. 1st ed. Brooklandville, MD, USA: Data Trace Media; 2007. 
32. Császár NB, Schmitz C. Extracorporeal shock wave therapy in musculoskeletal disorders. J Orthop Surg Res. 2013;8:22.

33. Gerdesmeyer L, Maier M, Haake M, Schmitz C. [Physicaltechnical principles of extracorporeal shockwave therapy (ESWT)]. Orthopade. 2002;31:610-617. German.

34. Trademark Electronic Search System (TESS) of the United States Patent and Trademark Office. Available from: http://www.uspto.gov/ trademarks/index.jsp. Serial Number 79065686; Registration Number 3712310 .

35. Trademark Electronic Search System (TESS) of the United States Patent and Trademark Office. Available from: http://www.uspto.gov/trademarks/ index.jsp. Serial Number 77249758; Registration Number 3593746.

36. DePace R. Pulsed-activated therapy. J Foot Ankle Surg. 2011;50:783.

37. Saxena A, Ramdath S Jr, O'Halloran P, Gerdesmeyer L, Gollwitzer H. Pulsed-activated therapy. J Foot Ankle Surg. 2011;50:783-784.

38. Concept Clinic. Extracorporeal Shock Wave Treatment for Cellulite. Available from: http://clinicaltrials.gov/ct2/show/NCT01974115. NLM identifier: NCT01974115. Accessed May 11, 2014.

39. Shaffer JP. Multiple hypothesis testing. Annu Rev Psychol. 1965;46: 561-584.

40. Cleveland RO, Chitnis PV, McClure SR. Acoustic field of a ballistic shock wave therapy device. Ultrasound Med Biol. 2007;33:1327-1335.

41. Perez C, Chen H, Matula TJ, Karzova M, Khokhlova VA. Acoustic field characterization of the Duolith: measurements and modeling of a clinical shock wave therapy device. J Acoust Soc Am. 2013;134:1663-1674.

42. Saxena A, Ramdath S Jr, O'Halloran P, Gerdesmeyer L, Gollwitzer H. Extra-corporeal pulsed-activated therapy ("EPAT" sound wave) for Achilles tendinopathy: a prospective study. J Foot Ankle Surg. 2011;50: 315-319.

43. European Medicines Agency. Guideline on missing data in confirmatory clinical trials. 2010. Available from: http:/www.ema.europa. eu/docs/en_GB/document_library/Scientific_guideline/2010/09/ WC500096793.pdf. Accessed May 11, 2014.

44. Ferraro GA, De Francesco F, Cataldo C, Rossano F, Nicoletti G, D’Andrea F. Synergistic effects of cryolipolysis and shock waves for noninvasive body contouring. Aesthetic Plast Surg. 2012;36: 666-679.

45. Maier M, Averbeck B, Milz S, Refior HJ, Schmitz C. Substance P and prostaglandin E2 release after shock wave application to the rabbit femur. Clin Orthop Relat Res. 2003;406:237-245.

46. Klonschinski T, Ament SJ, Schlereth T, Rompe JD, Birklein F. Application of local anesthesia inhibits effects of low-energy extracorporeal shock wave treatment (ESWT) on nociceptors. Pain Med. 2011;12:1532-1537.

47. Snijdelaar DG, Dirksen R, Slappendel R, Crul BJ. Substance P. Eur J Pain. 2000;4:121-135.

48. Burks TF, Buck SH, Miller MS. Mechanisms of depletion of substance P by capsaicin. Fed Proc. 1985;44:2531-2534.

49. Quatresooz P, Piérard GE. Immunohistochemical clues at aging of the skin microvascular unit. J Cutan Pathol. 2009;36:39-43.

50. Mlosek RK, Woźniak W, Malinowska S, Lewandowski M, Nowicki A. The effectiveness of anticellulite treatment using tripolar radiofrequency monitored by classic and high-frequency ultrasound. $J$ Eur Acad Dermatol Venereol. 2012;26:696-703.

51. Nootheti PK, Magpantay A, Yosowitz G, Calderon S, Goldman MP. A single center, randomized, comparative, prospective clinical study to determine the efficacy of the VelaSmooth system versus the Triactive system for the treatment of cellulite. Lasers Surg Med. 2006;38:908-912.

52. Goldberg DJ, Fazeli A, Berlin AL. Clinical, laboratory, and MRI analysis of cellulite treatment with a unipolar radiofrequency device. Dermatol Surg. 2008;34:204-209.

53. Sadick NS, Mulholland RS. A prospective clinical study to evaluate the efficacy and safety of cellulite treatment using the combination of optical and RF energies for subcutaneous tissue heating. $J$ Cosmet Laser Ther. 2004;6:187-190.

54. Sadick N, Magro C. A study evaluating the safety and efficacy of the VelaSmooth system in the treatment of cellulite. J Cosmet Laser Ther. 2007;9:15-20.
55. Prado A, Andrades P, Danilla S, Leniz P, Castillo P, Gaete F. A prospective, randomized, double-blind, controlled clinical trial comparing laser-assisted lipoplasty with suction-assisted lipoplasty. Plast Reconstr Surg. 2006;118:1032-1045.

56. Nagy MW, Vanek PF Jr. A multicenter, prospective, randomized, single-blind, controlled clinical trial comparing VASER-assisted lipoplasty and suction-assisted lipoplasty. Plast Reconstr Surg. 2012;129 (4):681e-689e.

57. Katz B, McBean J, Cheung JS. The new laser liposuction for men. Dermatol Ther. 2007;20:448-451.

58. Kim KH, Geronemus RG. Laser lipolysis using a novel $1064 \mathrm{~nm}$ Nd:YAG laser. Dermatol Surg. 2006;32:241-248.

59. Lis-Balchin M. Parallel placebo-controlled clinical study of a mixture of herbs sold as a remedy for cellulite. Phytother Res. 1999;13: 627-629.

60. Kligman AM, Pagnoni A, Stoudemayer T. Topical retinol improves cellulite. J Dermatol Treat. 1999;10:119-125.

61. Sasaki GH, Oberg K, Tucker B, Gaston M. The effectiveness and safety of topical PhotoActif phosphatidylcholine-based anti-cellulite gel and LED (red and near-infrared) light on Grade II-III thigh cellulite: a randomized, double-blinded study. J Cosmet Laser Ther. 2007;9: 87-96.

62. Moreno-Moraga J, Valero-Altés T, Riquelme AM, Isarria-Marcosy MI, de la Torre JR. Body contouring by non-invasive transdermal focused ultrasound. Lasers Surg Med. 2007;39:315-323.

63. Collis N, Elliot LA, Sharpe C, Sharpe DT. Cellulite treatment: a myth or reality: a prospective randomized, controlled trial of two therapies, endermologie and aminophylline cream. Plast Reconstr Surg. 1999; 104:1110-1114.

64. Chang P, Wiseman J, Jacoby T, Salisbury AV, Ersek RA. Noninvasive mechanical body contouring: (Endermologie) a one-year clinical outcome study update. Aesthetic Plast Surg. 1998;22:145-153.

65. Smalls LK, Hicks M, Passeretti D, et al. Effect of weight loss on cellulite: gynoid lypodystrophy. Plast Reconstr Surg. 2006;118: 510-516.

66. Mauriège $\mathrm{P}$, Imbeault $\mathrm{P}$, Langin $\mathrm{D}$, et al. Regional and gender variations in adipose tissue lipolysis in response to weight loss. J Lipid Res. 1999;40:1559-1571.

67. Hexsel DM, Serra M, Mazzuco R, Dal'Forno T, Zechmeister D. Phosphotidylcholine in the treatment of localized fat. J Drugs Dermatol. 2003;2:511-518.

68. Rotunda AM, Suzuki H, Moy RL, Kolodney MS. Detergent effects of sodium deoxycholate are a major feature of an injectable phosphatidylcholine formulation used for localized fat dissolution. Dermatol Surg. 2004;30:1001-1008.

69. Brandi C, D'Aniello C, Grimaldi L, et al. Carbon dioxide therapy in the treatment of localized adiposities: clinical study and histopathological correlations. Aesthetic Plast Surg. 2001;25:170-174.

70. Brandi C, D'Aniello C, Grimaldi L, Caiazzo E, Stanghellini E. Carbon dioxide therapy: effects on skin irregularity and its use as a complement to liposuction. Aesthetic Plast Surg. 2004;28:222-225.

71. Coleman WP. Liposuction. In: Coleman WP, Hanke CW, Alt TH, editors. Cosmetic Surgery of the Skin: Principles and Practice. 1st ed. Philadelphia, PA, USA: BC Decker; 1991.

72. Môle B. La lipolyse chimique sous-cutanee par la phosphatidylcholine: une experience de cinq annees [A five years experience of subcutaneous chemical lipolysis with phosphatidylcholine injections]. Ann Chir Plast Esthet. 2011;56:112-119. French.

73. Manstein D, Laubach H, Watanabe K, Farinelli W, Zurakowski D, Anderson RR. Selective cryolysis: a novel method of non-invasive fat removal. Lasers Surg Med. 2008;40:595-604.

74. Hexsel DM, Mazzuco R. Subcision: a treatment for cellulite. Int $J$ Dermatol. 2000;39:539-544.

75. Canadian Task Force on the Periodic Health Examination. The periodic health examination. Can Med Assoc J. 1979;121:1193-1254.

76. Siems W, Grune T, Voss P, Brenke R. Anti-fibrosclerotic effects of shock wave therapy in lipedema and cellulite. Biofactors. 2005;24: 275-282. 


\section{Publish your work in this journal}

Clinical, Cosmetic and Investigational Dermatology is an international, peer-reviewed, open access, online journal that focuses on the latest clinical and experimental research in all aspects of skin disease and cosmetic interventions. All areas of dermatology will be covered; contributions will be welcomed from all clinicians and basic science researchers globally. This journal is indexed on CAS. The manuscript management system is completely online and includes a very quick and fair peer-review system, which is all easy to use. Visit http://www.dovepress.com/testimonials.php to read real quotes from published authors.

Submit your manuscript here: http://www.dovepress.com/clinical-cosmetic-and-investigational-dermatology-journal 